\title{
O DESAFIO DA GESTÃO DE RESÍDUOS SÓLIDOS URBANOS
}

Os resíduos sólidos urbanos (RSU) tornaram-se um assunto de grande preocupação pública. No Brasil, apesar da instalação de medidas de coleta seletiva, grande parte dos resíduos não é direcionada para reciclagem

\footnotetext{
A temática dos resíduos sólidos urbanos (RSU), hoje, constitui um desafio importante para a gestão das cidades em direção à sustentabilidade. Entretanto, os fenômenos e os impactos relacionados à prevenção, geração, coleta, disposição e reaproveitamento dos RSU têm sido tratados setorialmente, de maneira desarticulada, obstruindo uma visão sistêmica do problema e refletindo-se em políticas públicas fragmentadas. Para os gestores públicos de todo o mundo, o gerenciamento de resíduos sólidos tornou-se, nas
} 


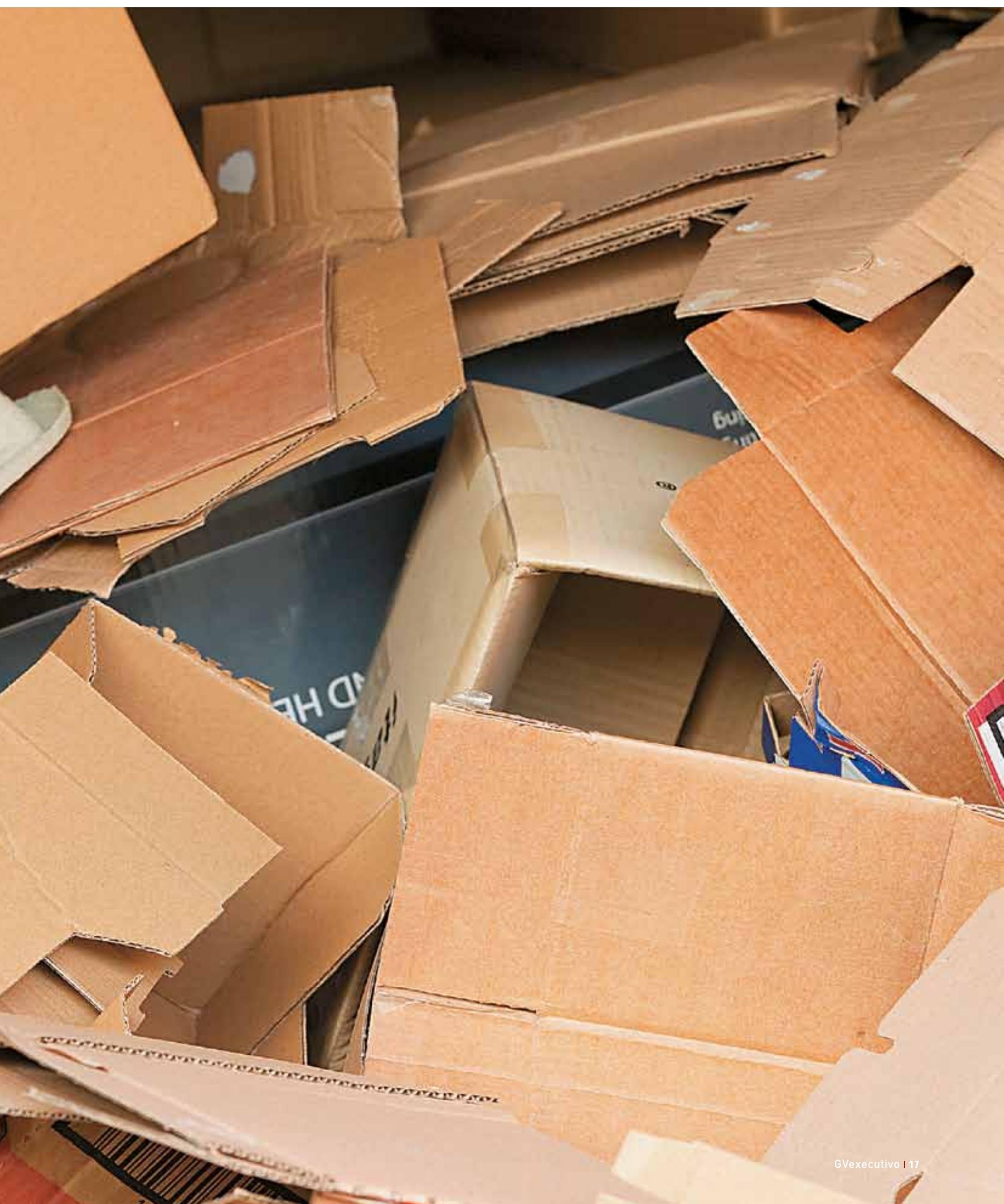


últimas décadas, um tema de preocupação. Segundo a Organização das Nações Unidas (ONU), a atual geração de resíduos no mundo gira em torno de 12 bilhões de toneladas/ano e, até 2020, o volume previsto é de 18 bilhões de toneladas/ano. Levantamento realizado pela Associação Brasileira de Empresas de Limpeza Pública e Resíduos Especiais (Abrelpe) mostra que o volume de RSU gerado no Brasil foi de 60 milhões de toneladas/ano em 2010, $6,8 \%$ superior ao ano anterior.

\section{As soluções relacionadas aos RSU têm sido tratadas de maneira desarticulada, impedindo uma visão ampla do problema e refletindo políticas públicas fragmentadas}

\section{MAIS DINHEIRO, MAIS RESÍDUOS. A relação entre desenvol-} vimento econômico e geração de resíduos é direta: quanto mais próspero o país, mais RSU gerado. Assim, o aumento do poder aquisitivo, somado ao aumento da população e o crescente consumo de materiais descartáveis, contribuem para o problema do rápido esgotamento dos aterros sanitários e a poluição gerada pela disposição indevida. Na verdade, a alteração da composição do RSU doméstico, provocada pelas inovações tecnológicas em materiais para produtos de uso diário, o acelerado consumo e descarte têm gerado um justificado temor sobre um futuro abarrotado de enormes montanhas do chamado "lixo branco". Ou seja, polímeros com média ou baixa reciclabilidade, basicamente porque o custo de sua recuperação ainda é superior à obtenção da matéria-prima virgem.
Apesar de haver tecnologia para reciclagem da grande maioria dos materiais utilizados para compor as embalagens de alimentos, por exemplo, é necessária a sua absorção pelo circuito da indústria da reciclagem. Além disso, há resíduos que não podem ser reutilizados, por diferentes razões: higienização, impossibilidade de desmontagem, dificuldade de correta identificação e separação dos materiais, compartimentos, sistemas e subsistemas que compõem um produto já descartado.

0 ALTO CUSTO. É fundamental ressaltar que os custos financeiros e ambientais para gerenciar o expressivo volume de RSU são enormes para as sociedades. A ONU estima que de 20\% a 30\% dos orçamentos das cidades são despendidos na coleta e disposição dos resíduos. Por exemplo, São Paulo, a maior metrópole da América Latina, com mais de 11 milhões de habitantes, enfrenta vários desafios na gestão de seus resíduos sólidos. Diariamente, são geradas em torno de 17 mil toneladas de resíduos, das quais cerca de 12 mil são domiciliares e de feiras livres; o restante engloba varrição, poda de árvores, entulhos e resíduos hospitalares, sob responsabilidade da prefeitura.

A gestão de resíduos sólidos urbanos em cidades como São Paulo exerce um impacto considerável no orçamento municipal. Paga-se para "enterrar" resíduos que, muitas vezes, poderiam ser primeiramente reduzidos ou, então, reciclados. Os gastos com os serviços de limpeza urbana da cidade de São Paulo, em 2009, foram de R \$ 967.503.647 (SNIS, 2011), o que equivaleu a $4 \%$ do orçamento municipal naquele ano. Assim, o destino final da maior parte dos resíduos gerados pelos domicílios paulistanos continua sendo o aterro. Um dos problemas operacionais dessa solução é que os aterros estão ficando cada vez mais distantes. A primeira razão é explicada pela expressão NIMBY (not in my backyard, traduzido como "não no meu quintal"), que expri- 
me o consenso de que ninguém quer lixo perto de casa. A segunda é que a valorização do metro quadrado aumenta o custo dos terrenos próximos à região central das cidades. Não há áreas disponíveis no perímetro urbano que ofereçam possibilidades para construção de novos aterros e, dessa forma, os resíduos não reaproveitados são transportados para aterramento em locais cada vez mais distantes.

AVANÇOS E DIFICULDADES. Uma solução para diminuir os resíduos depositados nos aterros surge com os programas municipais de coleta seletiva de materiais recicláveis. Cidades como Curitiba, Belo Horizonte e São Paulo, por exemplo, têm realizado a coleta seletiva de materiais recicláveis a partir das Centrais de Triagem, nas quais os materiais são classificados, separados, prensados e, por fim, comercializados pelas cooperativas de catadores conveniadas às prefeituras. Embora tenha havido avanços nessa solução, tais programas revelam suas fragilidades. Por exemplo, em São Paulo, menos de 1\% do total dos resíduos gerados diariamente é efetivamente encaminhado para reciclagem. Ao se considerar o quanto é selecionado em relação ao volume de resíduos gerados no município, percebe-se que o programa precisa ser ampliado e que há um longo caminho a se percorrer, marcado por muitos desafios.

VALORIZAÇÃO AOS CATADORES. Apesar das deficiências em infraestrutura das cidades brasileiras, muitas vezes é a cadeia informal de reciclagem que consegue reinserir o material nos processos produtivos. Essa cadeia conta, primordialmente, com a mão de obra dos catadores, seja de maneira independente, cooperativada ou organizada em redes, que trabalham em condições precárias e subumanas. Nesse sentido, cabe às prefeituras uma atenção especial, uma valorização do trabalho dos catadores, ao implantar

\section{Apesar de não terem seu trabalho valorizado, são os catadores que conseguem reinserir o material nos processos produtivos}

um sistema de gestão integrado de resíduos sólidos, conforme aponta a Política Nacional de Resíduos Sólidos, em sua Lei 12.305/2010.

Essa lei trata diretamente dos temas referentes à sustentabilidade, inserção dos catadores, design de produtos, logística reversa e responsabilidade compartilhada pelo ciclo de vida do produto. Ela dispõe sobre ampla temática da gestão integrada de resíduos sólidos nos municípios brasileiros, que necessita ser considerada à luz de aspectos socioambientais e comportamentais a ela relacionados. Essa medida também versa sobre a disposição final ambientalmente adequada dos resíduos, tomando por base a prevenção, redução, reutilização, reciclagem, tratamento dos resíduos sólidos e disposição final dos rejeitos. Estabelece prazos para seu cumprimento, sendo que os Planos Estaduais e Municipais de gestão de resíduos sólidos devem estar prontos até agosto de 2012, e a disposição final ambientalmente adequada dos rejeitos deve ser implementada até agosto de 2014. 
NOVAS ALTERNATIVAS. Diante da emergência e institucionalização dessa política, é necessário ampliar os estudos, pesquisas e debates entre os atores sociais para subsidiar a implementação do referido instrumento legal. Além disso, é importante que consumidores, produtores, distribuidores e varejistas participem dessa política, cada qual com papéis definidos. Isso inclui a busca de múltiplas soluções, entre as quais:

1. estruturas de incentivo (impostos, subsídios e penalidades);

2. condições e fatores situacionais (acesso a programas de reciclagem, rede logística, entre outros);

3. contexto institucional (regras, regulamentações, estruturas de mercado);

4. contexto social e cultural (força da comunidade, a estabilidade familiar, entre outros);

5. práticas comerciais com menores impactos;

6. envolvimento das comunidades e bairros, para que possam melhorar sua própria qualidade de vida.

REFLEXÃo. Ainda que o ritual cotidiano da deposição-descarte, coleta-recuperação e reciclagem que acontece no espaço público das metrópoles contemporâneas nos faça repensar os impasses e paradoxos da sociedade, este ato público manifesta uma convergência significativa das questões ambientais, sociais e da pobreza urbana, forçando a emergência de reflexões sobre o sistema de produção-consumo ao qual a sociedade atual está submetida. O que devemos perguntar é: o que fazer com os restos do consumo?

Embora a questão dos resíduos sólidos aponte desafios comuns, não há uma única solução, pois é preciso considerar a especificidade da cultura do descarte e do padrão de desenvolvimento socioeconômico. Há uma diversidade de vertentes relativas ao tema: aspectos legais, inovação tecnológica, reaproveitamento, tratamento dos resíduos, geração

\section{Políticas de educação ambiental, mudanças nos hábitos e atitudes dos cidadãos são fundamentais para a redução e prevenção na geração de resíduos}

de energia, mudanças de comportamento, entre outras. Todas elas estão interconectadas e requerem abordagens inovadoras e metodologias interdisciplinares, mas é premente estudar, debater e envolver amplamente a sociedade em torno desse tema. Além disso, é fundamental articular o diálogo com equipes de profissionais, como advogados, administradores, engenheiros, geógrafos e demais profissionais da área socioambiental.

Essas evidências apontam para a gestão integrada dos resíduos sólidos como um grande desafio para as metrópoles deste início de século. Nesse sentido, há necessidade de formulação de políticas públicas que priorizem a articulação intersetorial e fomentem a educação ambiental e mudanças nos hábitos e atitudes dos cidadãos, visando a redução e prevenção na geração de resíduos. Uma estratégia concentrada é necessária para facilitar o comportamento almejado, garantindo que as estruturas de incentivo e as regras institucionais favoreçam o encaminhamento de medidas rumo à sustentabilidade.

SYLMARA GONÇALVES DIAS, professora da EACH-USP,

sylmaraldias@gmail.com 